\title{
Tetrapod swim techniques interpreted from swim trace fossils from the Lower Triassic Baranów Formation, Holy Cross Mountains, central Poland
}

\author{
Grzegorz Sadlok $^{1} \cdot$ Krzysztof Pawełczyk $^{1}$
}

Received: 18 June 2019 / Accepted: 28 December 2019 / Published online: 29 January 2020

(c) The Author(s) 2020

\begin{abstract}
Swimming tetrapods may leave their traces under water if their digits or limbs stir the bottom sediment. Resulting trace fossils are evidence of a swim behavior. Tetrapods swim techniques depend on the functional morphology of the swimmers. Examination of swim trace fossils may reveal the swim techniques employed and swimmers' functional morphologies behind the behaviors. The present paper analyzes swim trace fossils of tetrapods from the fluvial Lower Triassic Baranów Formation in the Holy Cross Mountains (central Poland). The examination focuses on swim techniques. An attempt is made to correlate the inferred technique with functional morphology of the swimmer. It is concluded that the two types of swim traces occur in the Baranów Formation. These record two different swim techniques-paddling with limbs and body/tail undulation. The distinct types of swim trace fossils point to two types of swimmers: fully terrestrial archosaurs paddling with their limbs and amphibious tetrapods swimming with undulatory movements-likely utilizing their laterally flattened tails.
\end{abstract}

Keywords Early triassic $\cdot$ Swimming tetrapods $\cdot$ Trace fossils $\cdot$ Swimming technique $\cdot$ Webbed foot $\cdot$ Archosaurs . Amphibians

\section{Introduction}

Terrestrial tetrapods may be occasional swimmers and swim if they need to cross a lake or river-for example, during migrations (see, e.g., Yeager 1991) or exceptionally—during the hunt-escape situation (see, e.g., Sweeney et al. 1971; Nelson and Mech 1984; Jordan et al. 2010). Other tetrapods have amphibious life styles-they stay close to, or in the water and swimming is very much a part of their daily behavioral repertoire (see, e.g., Somers and Purves 1996; Barbraud and Weimerskirch 2001; Seebacher et al. 2003; Willson et al. 2006). In any of those cases, tetrapods may stir the muddy sediment on the bottom with their limbs/digits and produce swim traces. Traces of swim behavior may pass into the fossil record. If they do so, they become a matter

Handling Editor: Mike Reich.

Grzegorz Sadlok

gregsadlok@gmail.com of interest for ichnologists who analyze and classify such fossilized traces of locomotion as repichnia (sensu Vallon et al. 2016). Swim trace fossils are meaningful and important piece of information on swim behaviors (e.g., Sarjeant 1975).

The functional morphology puts physical constrains on the way the vertebrates propel themselves in water. Fish, amphibians, amphibious reptiles (e.g., crocodiles), terrestrial and marine mammals swim in various ways (see, e.g., Webb 1988; Fish 1996). The details of swim behavior can be preserved in and deciphered from trace fossil morphology.

The Lower Triassic Baranów Formation from the Holy Cross Mountains (central Poland) is a fluvial formation. Its sediments are rich in trace fossils, including tetrapod swim traces (Kuleta et al. 2005; Bujok et al. 2008). Despite the abundance of those swim ichnites, the detailed analysis of behaviors and trackmakers these traces represent has been lacking. The present paper aims to fill that void and examines the swim techniques and potential identities of the swimmers.

1 Faculty of Natural Sciences, Institute of Earth Sciences, University of Silesia in Katowice, Będzińska 60, PL-43-200 Sosnowiec, Poland 


\section{Geological settings}

The strata constituting the Baranów Formation are Lower Triassic deposits representing braided fluvial system (Kuleta and Nawrocki 2000; Kuleta et al. 2005; Bujok et al. 2008). The formation outcrops at the northern margin of the Holy Cross Mountains-north of city of Kielce (central Poland, Fig. 1a-c).

The formation comprises two main lithofacies: reddish mudstones and sandstones-representing floodplain and channel subenvironments, respectively (see Kuleta et al. 2005, see fig. 2 therein and Fig. 1 herein). The thicknesses and proportions of the lithofacies are variable-mudstone intervals become thicker in the upper part of the Baranów Formation. Sandstones associated with mud-dominated intervals tend to form thinner beds (Kuleta et al. 2005; Bujok 2007). The contacts between mudstones and sandstones (sandstones-over-mudstones) are sharp to erosive (Fig. 1e-g). Locally, inclined sharp to erosive contacts are observed within sandstone packages (Fig. 1e). Thicker sandstone-dominated intervals display upward thinning trends (Fig. 1e) - an indication of channel evolution (Walker and Douglas 1984). The thickest sandstone intervals show remnants of trough cross bedding (Fig. 1g) - a record of in-channel bed forms migration. Locally, surfaces with pebble-rich lags (mudclasts) and scour-and-fill gutters (cf. Shukla et al. 2006) are also observed (Fig. 3a).

A rich trace fossil assemblage (root traces, invertebrate and vertebrate ichnites; Figs. 1, 2 and 3) occurs in the formation (see, e.g., Kuleta et al. 2005; Bujok 2007; Bujok et al. 2008). Regarding the composition and preservation of trace fossils-e.g., the high abundance of tetrapod swim traces, the strata from Baranów resemble those from the lower Triassic Moenkopi Formation (Utah, USA; Thomson and Droser 2015). The trace fossils are mostly associated with lower surfaces of the sandstone beds (Fig. 1h-i).

\section{Material}

The present study is based on material (Figs. 2 and 3) from Baranów quarry where the Baranów Formation outcrops (Fig. 1). The quarry is an active mining site and the studied specimens were found ex situ, on excavated blocks of sandstone. The location of findings and their presumed stratigraphic proveniences are shown in Fig. 1d. The studied material includes two large specimens photographed during our field work in autumn of 2018 (Fig. 3) and material stored in the Museum of Institute of Earth Sciences of the University of Silesia, in Sosnowiec (Fig. 2, museum labels: WNoZ/S/7/62 and 258).
The ichnites were photographed, measured and their interpretative drawings were made. The applied terminology follows mostly McAllister (1989); it uses terms like footmark and footmarks to refer to swim traces. Associated sequence of footmarks is a traceway in McAllister (1989) terminology; however, we use more general and widely known term trackway to address such a sequence.

\section{Description}

\section{Parallel ridges}

These trackways are preserved on lower surfaces of centimeter- to decimeter-thick sandstone beds (convex hypichnia), herein referred to as specimens WNoZ/S/7/62 and $\mathrm{WNoZ/S/7/258.}$

Specimen WNoZ/S/7/62 There are four imprints (I-IV) visible on the specimen WNoZ/S/7/62 (Fig. 2a); measurements of length, width and relief are provided in Table 1. Two distinct morphologies are present (Fig. 2a-f). Footmarks I and II are sets of ridges. These two are almost identical in terms of their morphology and symmetry (Fig. 2b, c). These are described in details below. Tracks marked as III and IV are indistinct imprints, wider than longer (Fig. 2a).

Footmarks I and II are sets of long ridges (Fig. 2a-c). Each set comprises two narrow ridges $(21 \mathrm{~cm}$ long and $2-5 \mathrm{~cm}$ width) and one shorter and slightly wider $(18-19 \mathrm{~cm}$ long and 5-6 cm width). The ridges are parallel (Fig. 2a-c). The sets appear compact as the ridges contact each other (Fig. 2a-c). The outlines of the footmarks are sharp. The ridges taper on one end (Fig. 2b-c). Longitudinal striations are present on the sides of the ridges (inset in Fig. 2b). There are irregular depressions associated with the ridges (Fig. 2b, c). Simple horizontal to subhorizontal invertebrate trace fossils (small burrows, cf. Planolites and shallow burrows/ superficial furrows, cf. Helminthoidichnites) occur within the depressions and on the surface of sediment around the sets of ridges (Fig. 2a-e). The invertebrate trace fossils are cut, in places, by the sets of ridges (Fig. 2d). Distance between footmarks I and II-measured along the direction of their elongation-is approximately $50 \mathrm{~cm}$ (Fig. 2a, f). The distance measured perpendicular to that direction is approximately $19 \mathrm{~cm}$ (Fig. 2a, f). Desiccation cracks are cut (postdated) by the set of parallel ridges forming the imprint I (Fig. 2d).

Specimen WNoZ/S/7/258 There are three imprints (IIII) visible on the specimen WNoZ/S/7/258 (Fig. 2g); measurements of length, width and relief are provided in Table 1. Footmarks I-II are sets of parallel ridges (three per 

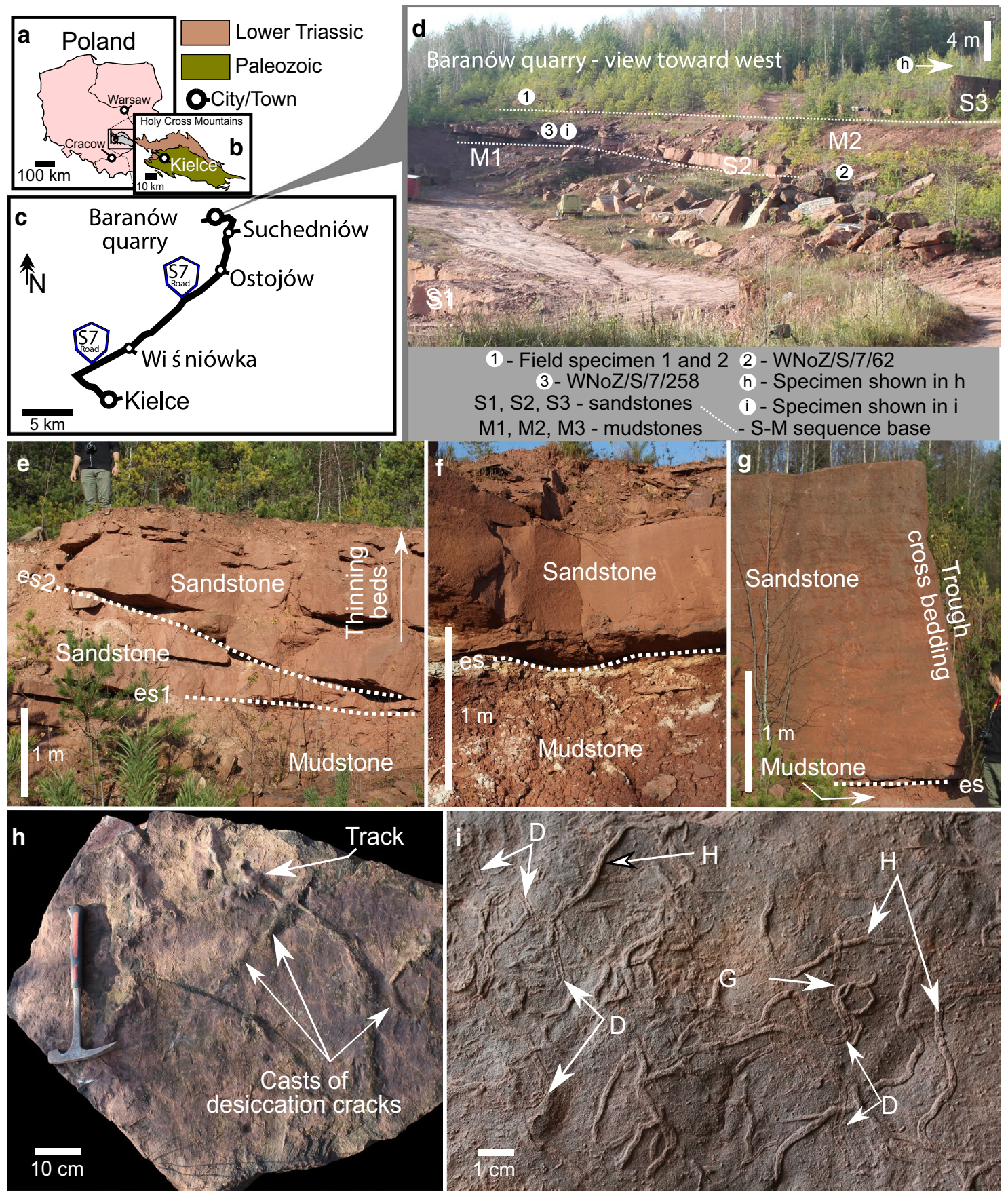

Fig. 1 Location of Baranów quarry in the Holy Cross Mountains and sedimentological summary of Baranów Formation. a Poland with outline of the Holy Cross Mountains; b The Holy Cross Mountains and location of major city-Kielce; c A map showing road S7 leading from Kielce to the Baranów quarry; $\mathbf{d}$ A view of Baranów quarry (a view toward west), main sandstone-mudstone sequences ( $\mathrm{S}-\mathrm{M}$ sequences) as seen in the central part of the quarry and collection/ finding points and stratigraphic provenience of the studied specimens (specimen shown in $\mathbf{h}$ has been photographed to the north from the main view); e Erosive contact between thick sandstone package and mudstone (es1) and inclined erosive contact within the sandstone package (es2); f Erosive contact between thinner sandstone bed and mudstone (es); $\mathbf{g}$ Thick sandstone interval with trough cross bedding (erosive contact with mudstones; es); $\mathbf{h}$ A sole of sandstone bed with casts of desiccation cracks and tetrapod track (field photograph); i An example of sandstone sole with multiple trails/shallow burrows of Helminthoidichnites (H), Diplopodichnus (D) and Gordia (G) (field photograph) 


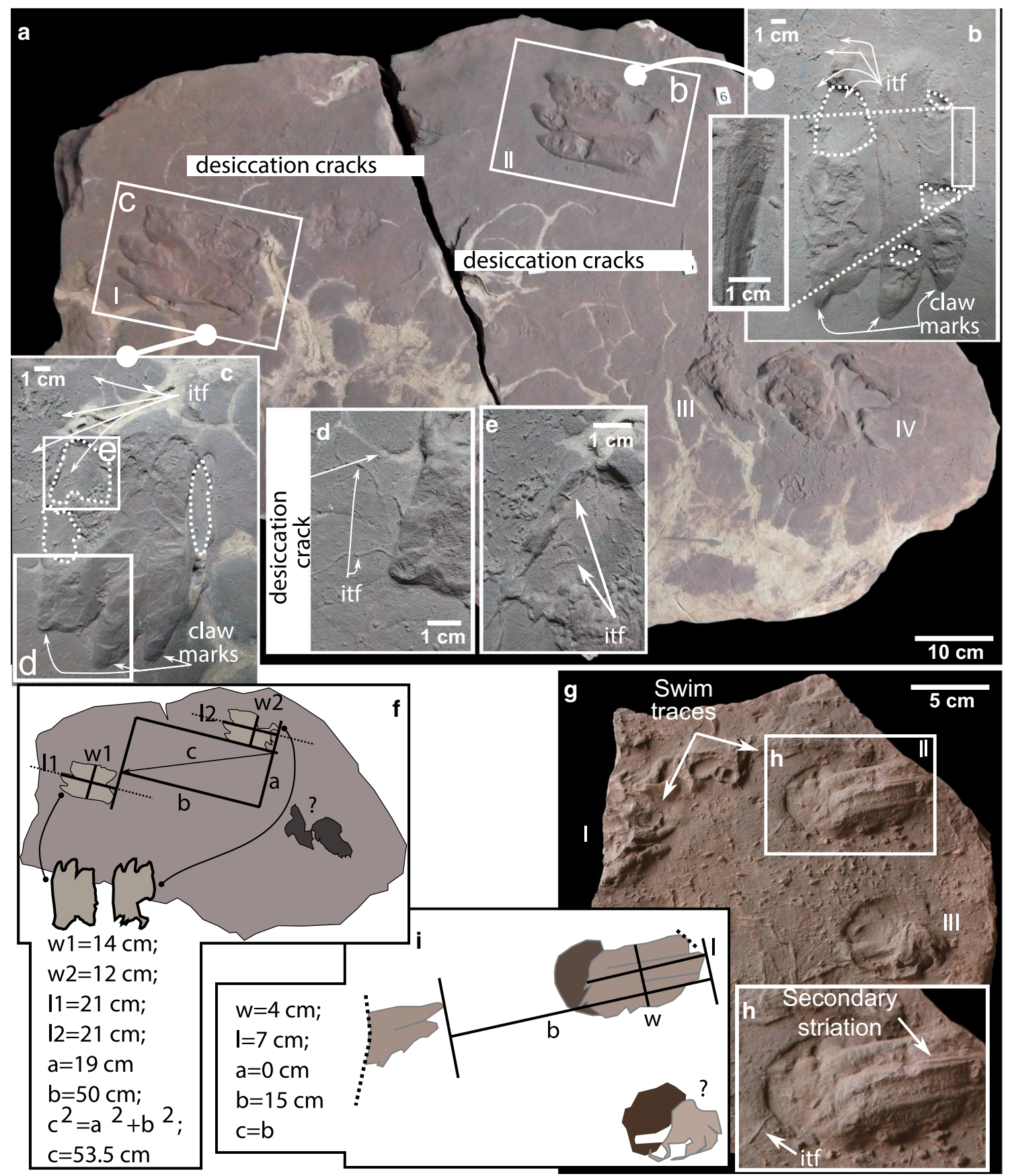

Fig. 2 Sets of parallel ridges - swim traces of paddling technique. a Specimen WNoZ/S/7/62 with footmarks (I-II) and indistinct footmarks III-IV; b Enlargement of footmark II, the inset shows longitudinal striations on the side of the footmark II (dotted lines outline depressions within the footmark); c Enlargement of footmark I (dotted lines outline depressions within the footmark); d Enlargement of detail from c, imprint cuts shallow horizontal to subhorizontal invertebrate trace fossils (itf) and desiccation crack; e Enlargement of detail from c, shows an irregular depression within the imprint and preserved shallow horizontal to subhorizontal invertebrate

footmark) and lie in one line (one after the other). Footmark I is incomplete, it terminates at the slab edge. Footmark II trace fossils (itf) within the depression; f An interpretative drawing of imprints seen in $\mathbf{a}$; Note: basic measurements are provided, the dashed lines represent axes of imprints; g Specimen WNoZ/S/7/258 with footprints (I-II) and a track (III); Note: crescent depressions associated with footmark II and track III; $\mathbf{h}$ Enlargement of detail from $\mathbf{g}$, shows crescent depression associated with footmark II and its cross-cutting relationship with invertebrate horizontal trace fossil (itf); i An interpretative drawing of imprints seen in $\mathbf{g}$; Note: basic measurements are provided

is close to the slab edge. It appears to be nearly complete as compared with footmark I. The distance between footmarks 

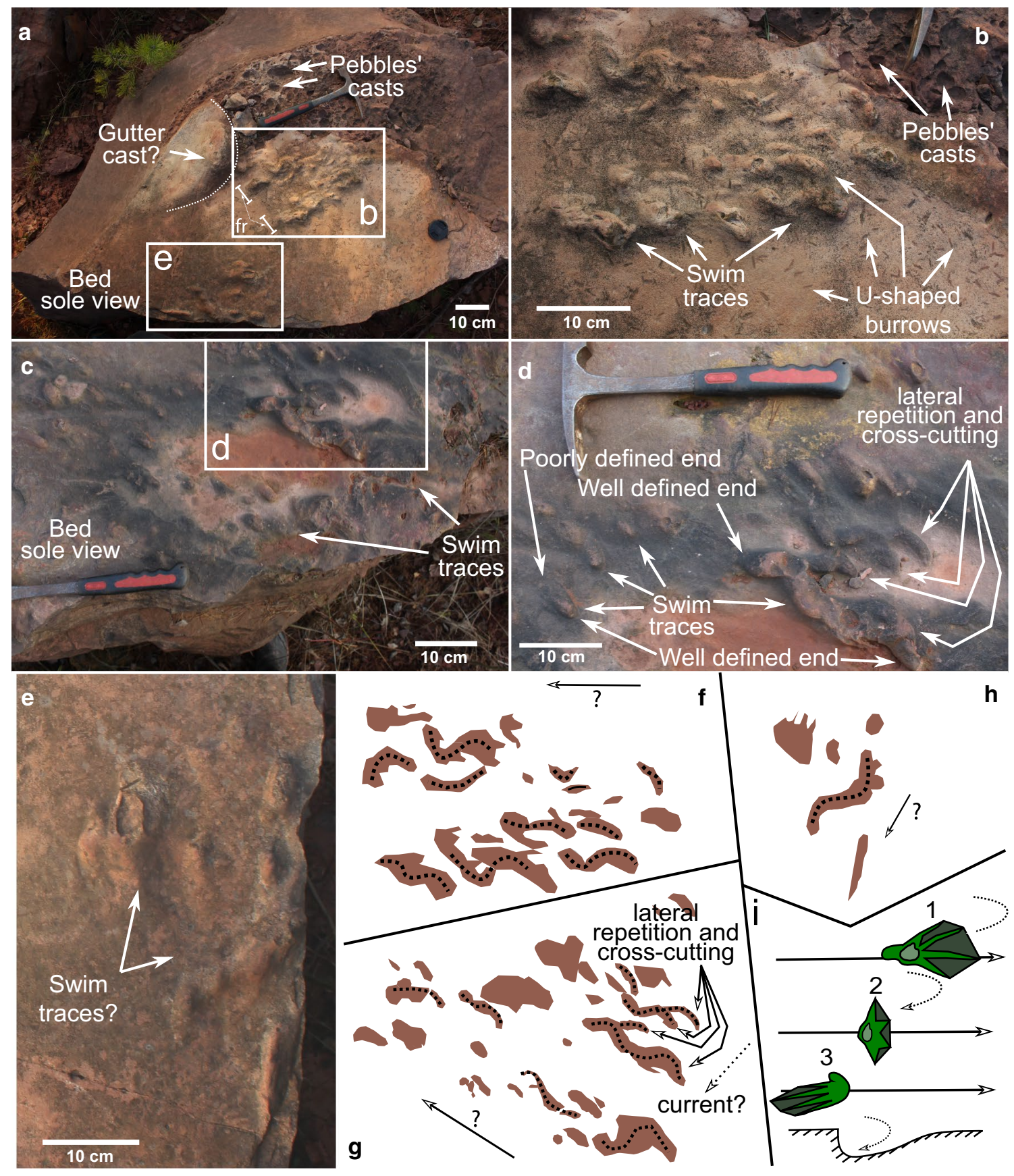

h

Fig. 3 Sine-shaped ridges-swim traces of undulatory technique. a A sandstone bed fragment (sole view) with sine-shaped ridges (swim traces), fr-footprints rows; the ridges are associated with U-shaped burrows and pebble-rich horizon (both postdate the ridges); b Enlarged part seen in a; c A sandstone bed fragment (sole view) with sine-shaped ridges (swim traces); d Enlarged part seen in c; e Enlarged part seen in a; $\mathbf{f}$ An interpretative drawing of swim traces from a (dotted line shows the sine-like shapes of imprints; arrow shows plausible swim direction, not to scale); g An interpretative drawing of imprints seen in $\mathbf{c}$ (meaning of dotted line as in $\mathbf{f}$; arrow shows plausible swim direction, not to scale); $\mathbf{h}$ An interpretative drawing of e (meaning of dotted line as in $\mathbf{f}$; arrow shows plausible swim direction, not to scale); i Schematic drawing showing the limb backstroke movement and the resulting relief of the trace (ridge in the trace fossil; a rowing foot with interdigital web is used on the illustration); the direction of swim is interpreted from changes in relieflower ends of ridges are thought to be entry spots of limb stirring the sediment; solid arrow shows plausible swimmer's move direction; dotted arrows show backstroke direction 
Table 1 The length, width and relief measurements of the tetrapod footmarks

\begin{tabular}{llllll}
\hline Specimen & Track/footprint & Length $(\mathrm{cm})$ & Width $(\mathrm{cm})$ & Relief $(\mathrm{cm})$ & Figures \\
\hline WNoZ/S/7/62 & I & 21 & 14 & $\leq 2$ & $2 \mathrm{a}, \mathrm{c}-\mathrm{e}$ \\
WNoZ/S/7/62 & II & 21 & 12 & $\leq 2$ & $2 \mathrm{a}, \mathrm{b}$ \\
WNoZ/S/7/62 & III & 6 & 12 & $\leq 2$ & $2 \mathrm{a}^{\mathrm{a}}$ \\
WNoZ/S/7/62 & IV & 9 & 15 & $\leq 2$ & $2 \mathrm{a}^{\mathrm{a}}$ \\
WNoZ/S/7/258 & I & Incomplete & Incomplete & $\leq 1$ & $2 \mathrm{~g}$ \\
WNoZ/S/7/258 & II & 7 & 4 & $\leq 1$ & $2 \mathrm{~g}$ \\
WNoZ/S/7/258 & III & 3.5 & 3.5 & $\leq 1$ & $2 \mathrm{~g}^{\mathrm{a}}$ \\
Field specimen 1 & Multiple & $\sim 2-20^{\mathrm{b}}$ & $\sim 1-3$ & $\leq 2$ & $3 \mathrm{a}, \mathrm{b}, \mathrm{e}$ \\
Field specimen 2 & Multiple & $\sim 4-20^{\mathrm{b}}$ & $\sim 1-3$ & $\leq 2$ & $3 \mathrm{c}-\mathrm{d}$ \\
\hline
\end{tabular}

${ }^{a}$ These specimens are not considered in detail in the present paper (indistinct morphologies)

${ }^{\mathrm{b}}$ Measured as straight line end-to-end
I and II is $15 \mathrm{~cm}$ (measured between tops of central ridges; Fig. 2g, i). Both sets of ridges are elongated. Their detail description is provided below. Track III is a more isometric imprint (width and length are approximately $3.5 \mathrm{~cm}$ ) and its digital imprints are curved-backward (Fig. $2 \mathrm{~g}$ ). It has a crescent-like depression at its rear end (Fig. 2g, i). Invertebrate trace fossils occur on the surface of sediment around the imprints (Fig. 2g) and some are cut by the imprints (Fig. 2h).

Footmark I is composed of ends of three ridges. These are separated by narrow groves (groves are narrower than the ridges). Footmark II has also three ridges; its length is $7 \mathrm{~cm}$ (Fig. 2g, i) and width is $4 \mathrm{~cm}$ (Fig. 2g, i). Footmark II has a crescent-like depression (approximately 1-2 mm deep) at one of its narrow ends (rear end; Fig. 2g, i). Millimeter-scale striation occurs on this footmark (Fig. $2 \mathrm{~g}, \mathrm{~h}$ ).

\section{Sine-shaped ridges}

These footmarks were observed on lower surfaces of decimeter-thick sandstone beds (convex hypichnia). One of the beds (Fig. 3a) shows pebble-grade material and millimeterscale U-shaped burrows associated with the footmarks. The U-burrows and pebble-grade material postdate the footmarks (Fig. 3a, b).

The footmarks are sine-shaped ridges (Fig. 3a-h). The measurements of length, width and relief are provided in Table 1 . The ridges are relatively deep and blunt on one end and pass gradually into the surrounding sediment on the other or show two blunt ends with one end having lower relief. Their surfaces are smooth. The sides of ridges are steep to weakly inclined and asymmetric. Some overlapping of the ridges may be seen locally (Fig. 3d, g). The footmarks form poorly defined trackways (Fig. 3a, f) and locally display lateral repetition (Fig. 3d, g).

\section{Discussion}

Swimming vertebrates use a set of movements to propel themselves through the water (Fig. 4). Their functional morphology constrains their swim techniques. Vertebrates swim in undulatory or oscillatory fashion. Fish, tadpoles, salamanders, crocodiles use body/tail lateral flexionundulatory movements - to swim. Fins of some fish, e.g., tuna tail, as well as limbs of frogs, reptiles, birds and most mammals are propellers being used in an oscillatory fashion (Webb 1988).

Undulatory body movements of axial propulsion may utilize various parts of a vertebrate body length. Based on the utilized part of the fish body, their swim techniques can be classified under four different categories: anguilliform, sub-carangiform, carangiform and thunniform (see McDowall 2003). These different techniques can be reflected in Undichna and Parundichna-sine-shaped trace fossils resulting from undulatory swim behaviors (e.g. Simon et al. 2003; Wisshak et al. 2004; Minter and Braddy 2006). Amphibious swimming tetrapods (e.g., salamander, alligator) may use similar techniques and flex the body/tail to swim (Bartholomew et al. 1976; Fish 1984; Hoff et al. 1989). Such amphibious tetrapods typically keep their limbs folded along their bodies when swimming by undulation of the body/tail (Fish 1984; Ijspeert et al. 2005). In shallow water, they switch from swimming to walking as their limbs get in contact with the substrate (see AshleyRoss and Bechtel 2004). 
a

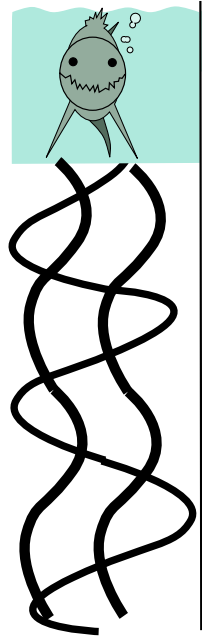

b

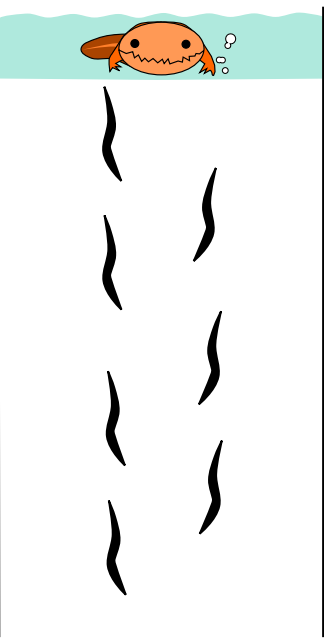

c

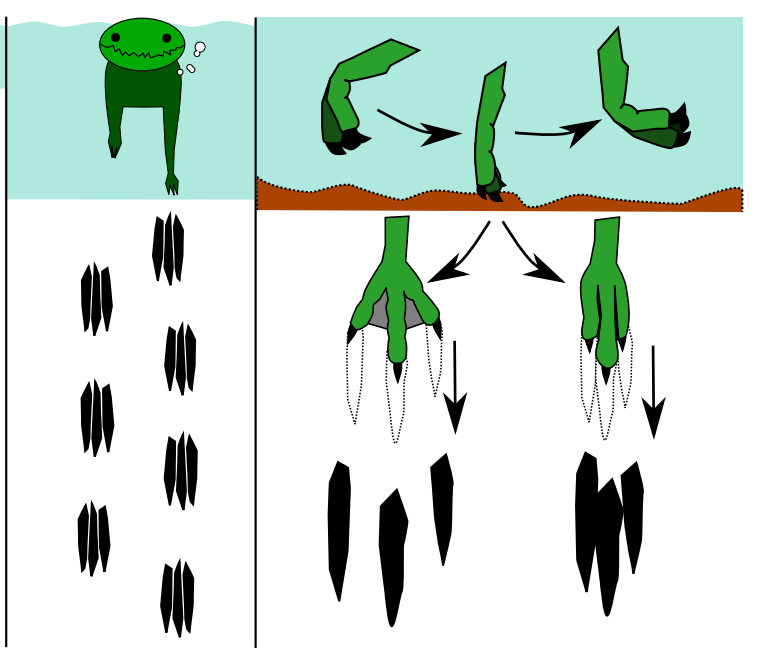

Fig. 4 Main swimming techniques of vertebrates. a Fish swimming with undulatory movements may produce sine-shaped continuous traces; b Tetrapod using undulatory swim technique may produces discontinuous sine-shaped imprints; c Tetrapod paddles with its erected limbs may leave indistinct scratches; d Sets of scratches may show two morphologies: spread and compact; it is shown how

Tetrapods may swim also using oscillatory techniquethey paddle or row with their limbs (Fish 2000; Fish and Baudinette 2008; Provini et al. 2012). The paddling is when limbs move in parasagittal plane-rowing, perpendicular to that plane (Fish 2000) and it may be performed in various ways: quadrupedal, pectoral and pelvic paddling (see Fish 1996, 2000). The paddling, especially its quadrupedal variant, is less efficient than other techniques and it reflects poor aquatic adaptation of terrestrial tetrapods that use it (Williams 1983; Fish and Baudinette 2008). Paddling is utilized by tetrapods with erect limbs, including the large ones, like elephants (Fish 1996). Dinosaurs likely used a paddling swim technique as well (e.g., Whyte and Romano 2001; Ezquerra et al. 2007).

Despite the fact that buoyancy affects the limb walk cycle (Ashley-Ross and Bechtel 2004), trackway pattern and its completeness (e.g., Lockley 1991), the detailed analysis may help to decipher tracemaker movements, their swim techniques and in some cases, anatomical features.

Before a sound analysis may be attempted, vertebrate footmarks created under water must be differentiated not only from inorganic structures (cf. Peabody 1947) but also from tracks and undertracks produced on a dry land (cf. McAllister and Kirby 1998). The criteria for the recognition of subaqueous formation involve features resulting from locomotion under buoyancy, movements of digits within the sediment, and action of currents generated by moving limbs. The criteria include: kick-off scours, z-traces, variable preservation of footmarks, posterior overhangs, longitudinal the foot, during the backstroke, scratches the sediment (dotted line: sediment/water boundary); it is proposed herein that the difference in scratch set morphology may reflect various foot behaviors during the backstroke phase, and variation in foot design (webbed vs. un-webbed feet)

striations on digit marks, variable footmark lengths and variable/incomplete trackway patterns (see McAllister and Kirby 1998; Thomson and Lovelace 2014). Thomson and Droser (2015) showed that morphologies of underwater footmarks depend also on substrate properties-firmground conditions allow preservation of fine morphological details, like longitudinal striations and displacement rims. Some of the proposed criteria, like kick-off scours, are susceptible to subsequent shallow erosion of mud. Some of the criteria excludes each other as their formation and preservation require different properties-kick-off scours require water-saturated and easily erodible sediment (see McAllister and Kirby 1998); whereas, the longitudinal striations require firmground settings (see Thomson and Droser 2015).

\section{Oscillatory swim technique}

Imprints left under water may represent walking or swimming. There are a few ichnogenera produced by dinosaurs, turtles and crocodiles while moving under partial buoyancy (e.g., Lockley 1991; Foster and Lockley 1997; McCrea et al. 2004; Lockley and Foster 2006; Ezquerra et al. 2007; Avanzini et al. 2010; Vila et al. 2014). Most of those ichnites (Chelonichnium, Chelonipus, Saltosauripus, Hatcherichnus), convey enough details of the autopodium anatomy to link them with their potential trackmakers. In those cases, the trackmakers' limbs were used to support, at least partially, their bodies, or to "feel" their way when they sensed they were close to the substrate. However, with increasing 
buoyancy only digits' tips can stir the bottom sediment and leave simple, indistinct scratches assignable to ichnogenera like Characichnos or Albertasuchipes-such swim traces cannot be associated with a specific tracemaker (Whyte and Romano 2001; McCrea et al. 2004; Vila et al. 2014; Ezquerra et al. 2007).

The sets of parallel ridges shown in Fig. 2 are vertebrate footmarks composed of digital scratches with no foot outline as would be expected from imprints resulting due to weightbearing phase of walking cycle executed over dry land (cf. Thulborn and Wade 1989). Irregular depressions (Fig. 2b, c) occur within footprints and indicate that these are the casts of elevations within the imprints. Those elevations could result from sediment of footmark edges collapsing or sliding into the footmark. Therefore, their presence and the presence of fine longitudinal striations seen on footmarks (inset in Fig. 3b) are taken as indications that the footmarks were originally open superficial features in relatively firm mud substrate rather than undertracks where such collapse structures and striations would not have occurred.

The shallow and superficial invertebrate trace fossils cooccur with the footmarks (see Fig. 2a, g). Some are preserved within the depressions of the footmarks and postdate them (Fig. 2b, c, e). The footmarks cut the invertebrate trace fossils (Fig. 2d, g, h) and, in places, desiccation cracks (Fig. 2d). In those cases, invertebrate trace fossils and desiccation cracks predate the footmarks. The presence of shallow invertebrate penetrations within the footmarks supports the view that these imprints have been left under water, close to or at the water-sediment interface. The superficial and/ or shallow invertebrate trace fossils preserved within the footmarks render undertrack origin unlikely.

The morphologies of ichnites, their sedimentological context and ichnological association suggest the footmarks are not undertracks and that they originated under water when the weight-bearing phase of the walking cycle was inhibited by the buoyancy of water.

Footmarks I and II on the specimen WNoZ/S/7/62 are very similar in terms of their morphology and symmetryboth have the shorter digit trace on the same side of their symmetry planes (Fig. 2f) and therefore, they are likely consecutive footmarks left by a single foot of a tracemaker (Fig. 2b, c). A mirror symmetry in morphology would be expected for footmarks and tracks left by opposite feet of the same animal. The footmarks' long axes are parallel but they do not sit on a single line (dashed lines in Fig. $2 \mathrm{f}$ are footmarks axes) - footmarks are separated by $19 \mathrm{~cm}$, measured perpendicular to their axes (see Fig. 2f). This pattern may suggest that the foot scratched the substrate at an angle to the swimming direction (cf. Thomson and Droser, 2015, fig. 3a therein). No such pattern can be assessed for footmarks I and II from the specimen WNoZ/S/7/258. This is because footmark I is incomplete and morphological similarity between the two cannot be fully assessed. Hence, a distinction between consecutive footmarks of opposite vs. the same foot cannot be made. Footmarks I and II on specimen WNoZ/S/7/258 appear similar in size and orientation and, therefore, could be produced by the same tracemaker. Footmarks on the specimen WNoZ/S/7/258 (Fig. $2 \mathrm{~g}-\mathrm{i}$ ) differ from those on the specimen WNoZ/S/7/62 (Fig. 2a, g) in the presence of crescent depression associated with the footmark II (Fig. 2g-i). This feature represents likely a cast of sediment displacement rim. The crescent depression and fine, millimeter-scale secondary striation of footmark II (Fig. 2g, h) may suggest a firmground properties of the substrate (cf. Thomson and Droser 2015).

The sets of parallel scratches (see footmarks I and II in Fig. 2a) resemble Characichnos with its general morphology and number of scratches in a footmark (see Whyte and Romano 2001; Bujok 2007). However, the studied material differs from Characichnos morphology described by Whyte and Romano (2001) with a compact appearance of sets which are composed of scratches contacting each other (Fig. 2). This difference may have behavioral and anatomical significance.

The propulsive effectiveness of the paddling propeller increases with its area-an interdigital web increases foot's paddling area and drag during propulsive backstroke in semiaquatic tetrapods (Fish 2000, and references therein). To achieve that, digits of webbed foot are spread during the propulsive backstroke (Fig. 4d). Therefore, they would create separated scratches - a typical spread morphology as in type material of Characichnos (cf. Whyte and Romano 2001). Crocodiles have interdigital webs on their feet and Characichnos assigned to them has not only spread scratches but also may in fact show traces of the web itself (cf. McCrea et al. 2004; Vila et al. 2014).

Contrary, close spacing of the scratches-a compact morphology, may indicate that swimmer lacking the webbed foot held its digits close together during the backstroke to increase the foot paddling area and effectiveness. A human palm can serve as analog - narrow gaps between digits increase slightly and optimize its paddling area and drag. However, they cannot increase over a certain threshold (e.g., $10^{\circ}-12^{\circ}$ of interdigital angle) without compromising the effectiveness of the propulsive backstroke (see Sidelnik and Young 2006; Minetti et al. 2009). Therefore, the compact morphology, as in the present footmarks, may result from action of an un-webbed foot with digits held close during the backstroke phase of the limb movement cycle (Fig. 4d) - this could be an example of behavior making up for the poor design of the propelling limb.

Both morphologies-spread and compact-of Characichnos are present in the strata from the Baranów Formation (see, e.g., Kuleta et al. 2005; Bujok et al. 2008). This may 
indicate two distinct types of tracemaker produced Characichnos from the unit.

The material studied herein suggests tracemakers with feet having no interdigital web-likely terrestrial tetrapods who crossed the body of water (Fig. 2). The tetrapod swim traces occur in strata comprising also ichnites of Chirotheriidae ichnofamily (Kuleta et al. 2005; Bujok 2007; Bujok et al. 2008). Archosaurs who produced such tracks (see Sarjeant 1975; Niedźwiedzki and Ptaszyński 2007) had no interdigital web as evidenced by their track morphology (cf. King et al. 2005). The ichnites of this ichnofamily are common in Triassic deposits (Sarjeant 1975; Leonardi and de Oliveira 1990; Ptaszyński 2000; Nicosia and Loi 2003; Fichter and Kunz 2004; King et al. 2005) and their archosaurian trackmakers are likely producers of the paddling traces described herein.

\section{Undulatory swim technique}

The sine-shaped ridges (Fig. 3) are likely footmarks produced by limbs stirring the bottom mud. Field specimen illustrated in Fig. 3b shows sections of U-shaped burrows associated with the ridges. The burrows represent Diplocraterion preservation style known from subaqueous deposits of Lower Triassic (see Gradziński and Uchman 1994). The burrows occur around the ridges and on the ridges indicating the invertebrate colonization took place after the ridges had been formed. The pebble-rich horizon occurs a few centimeters above the centimeter-thick sandstone layer casting the imprints (Fig. 3a, b). This pebbly horizon suggests the onset of high energy regime with deposition of lag within the channel. Therefore, the sandstone bed illustrates the high energy settings (pebble-grade lag deposition) postdated the period of low energy subaqueous settings when swim traces and U-burrows could form.

The ridges have smooth surfaces. This may suggest traces of individual digits have not been preserved either due to taphonomic filtration, due to blunt morphology of the foot (e.g., foot with extensive interdigital web and/or no claws) and smothering action of turbulent water flow emerging behind the limb during its backstroke movement (cf. Maglischo 2003; Matsuuchi et al. 2009). The flow depositing the casting sandstone could also smooth the imprint's morphology. The most characteristic feature of individual ridges is their sine-shaped morphology (Fig. 3a-e). Some shallower ridges (Fig. 3a-d) resemble flute casts (cf. Pollard 1985). However, clustering of ridges (Fig. 3a), sine-shaped morphology of larger ridges (Fig. 3b, d), cross-cutting relationships (Fig. 3d, g) and double well-defined ends seen in some ridges (Fig. 3d) indicate these are trace fossils. Closely spaced relatively short ridges may resemble-at a first glance-tracks/footmarks assignable to turtles. However, the ridges representing digital imprints of turtles form well-defined tracks and footmarks with no sine-shaped configuration (cf. Lockley and Foster 2006; Xing et al. 2014).

The sine-shaped component suggests undulation was likely superimposed on the progressive movement of the tracemaker. Regarding this feature, the sine-shaped swim traces resemble Lunichnium, which is thought to be a swim trace fossil of tetrapods, e.g., amphibians (Minter and Braddy 2006).

The trackway pattern is not clear. One can attempt to discern two footmark rows in the specimen illustrated in Fig. 3a. However, trackway pattern is much more elusive in specimen from Fig. 3c. Nevertheless, in both specimens, the ridges are closely spaced and locally overlap each other (Fig. 3d, g). Short distances between repetitive foot-substrate contacts may suggest the tracemaker climbed the inclined lake/river bed (cf. Ashley-Ross and Bechtel 2004) or it fought the current and swam upstream. In such a case, the progressive speed would be a resultant vector of tracemaker and the water current speeds.

The sine-shaped morphology suggests that undulatory swim technique was used and an amphibian or amphibious tracemaker produced the studied swim traces. The swimmers had likely a laterally compressed (deep) tails acting as propellers (cf. Fish 1984; Ashley-Ross and Bechtel 2004).

Kuleta et al. (2005) described from the Baranów Formation poorly preserved walking tracks of ?Capitosauroides and assigned the ichnites to amphibians. The studied swim traces support the evidence for the presence of water-adapted animals in the fluvial ecosystem represented by the Baranów Formation.

\section{Conclusion}

The tetrapods swim traces were analyzed from the Lower Triassic fluvial Baranów Formation from the Holy Cross Mountains (central Poland). Two main types of fossilized swim traces can be distinguished in these strata (Figs. 2 and $3)$ :

- Parallel scratch sets;

- Sine-shaped discontinuous imprints.

These two types of ichnites are thought to represent different swim techniques and swimmers. The trackways composed of scratch sets were likely produced by swimmers paddling with their limbs. These trackmakers, as all animals leaving their traces in the bottom muds, had to move through water which provided buoyancy to them. The studied footmarks show compact morphology - scratches in a set are in contact. This may indicate the tracemaker's foot had no interdigital web, contrary to animals responsible for swim 
traces composed of widely spaced scratches. Therefore, the tracemakers could be fully terrestrial tetrapods and likely crossed the water body due to their occasional needs (facultative swimmers).

In the case of parallel scratches, the tracemakers were likely the same archosaurs that produced tracks and trackways of Chirotheriidae ichnofamily - the inferred un-webbed foot matches the ichnofamily general track morphology.

Sine-shaped, discontinuous imprints were likely produced by swimmers utilizing the undulatory swim technique. Amphibians or amphibious reptiles with laterally flattened tails are likely candidates for the tracemakers. These swim traces provide evidence for the presence of amphibious tetrapods in the fluvial ecosystem represented by the Lower Triassic Baranów Formation.

Acknowledgements We are grateful to Martin Lockley (University of Colorado), Sebastian Voigt (Urweltmuseum GEOSKOP/Burg Lichtenberg) and Mike Reich (Munich, Editor-in-Chief of PalZ) and to an anonymous reviewer of PalZ. Their critics, valuable comments and suggestions greatly improved our manuscript.

Open Access This article is licensed under a Creative Commons Attribution 4.0 International License, which permits use, sharing, adaptation, distribution and reproduction in any medium or format, as long as you give appropriate credit to the original author(s) and the source, provide a link to the Creative Commons licence, and indicate if changes were made. The images or other third party material in this article are included in the article's Creative Commons licence, unless indicated otherwise in a credit line to the material. If material is not included in the article's Creative Commons licence and your intended use is not permitted by statutory regulation or exceeds the permitted use, you will need to obtain permission directly from the copyright holder. To view a copy of this licence, visit http://creativecommons.org/licenses/by/4.0/.

\section{References}

Ashley-Ross, M.A., and B.F. Bechtel. 2004. Kinematics of the transition between aquatic and terrestrial locomotion in the newt Taricha torosa. Journal of Experimental Biology 207(3): 461-474.

Avanzini, M., L. Piñuela, J.I. Ruiz-Omeñaca, and J. Garcia-Ramos. 2010. The crocodile track Hatcherichnus, from the Upper Jurassic of Asturias (Spain). New Mexico Museum of Natural History and Science, Bulletin 51: 89-92.

Barbraud, C., and H. Weimerskirch. 2001. Emperor penguins and climate change. Nature 411(6834): 183-186.

Bartholomew, G.A., A.F. Bennett, and W.R. Dawson. 1976. Swimming, diving and lactate production of the marine iguana, Amblyrhynchus cristatus. Copeia 1976(4): 709-720.

Bujok, A. 2007. Zespót skamieniatości śladowych z osadów aluwialnolitoralnych formacji z Baranowa, górny pstry piaskowiec, Góry Świetokrzyskie. Unpublished Master thesis. Sosnowiec: University of Silesia.

Bujok, A., G. Sadlok, G. Pieńkowski, and G. Niedźwiedzki. 2008. Stop 4-Baranów, Lower Triassic, Upper Spathian. In Ichnological sites of Poland: The Holy Cross Mountains and the Carpathian Flysch. The pre-congress and post-congress field trip guidebook, eds. G. Pieńkowski and A. Uchman, 54-59. Warszawa: Polish Geological Institute.
Ezquerra, R., S. Doublet, L. Costeur, P. Galton, and F. Pérez-Lorente. 2007. Were nonavian theropod dinosaurs able to swim? Supportive evidence from an Early Cretaceous trackway, Cameros Basin (La Rioja, Spain). Geology 35(6): 507-510.

Fichter, J., and R. Kunz. 2004. New genus and species of chirotheroid tracks in the Detfurth-Formation (Middle Bunter, Lower Triassic) of Central Germany. Ichnos 11(3-4): 183-193.

Fish, F.E. 1984. Kinematics of undulatory swimming in the American alligator. Copeia 1984(4): 839-843.

Fish, F.E. 1996. Transitions from drag-based to lift-based propulsion in mammalian swimming. Integrative and Comparative Biology 36(6): 628-641.

Fish, F.E. 2000. Biomechanics and energetics in aquatic and semiaquatic mammals: Platypus to whale. Physiological and Biochemical Zoology 73(6): 683-698.

Fish, F.E., and R.V. Baudinette. 2008. Energetics of swimming by the ferret: Consequences of forelimb paddling. Comparative Biochemistry and Physiology Part A: Molecular \& Integrative Physiology 150(2): 136-143.

Foster, J.R., and M.G. Lockley. 1997. Probable crocodilian tracks and traces from the Morrison Formation (Upper Jurassic) of eastern Utah. Ichnos 5(2): 121-129.

Gradziński, R., and A. Uchman. 1994. Trace fossils from interdune deposits-an example from the Lower Triassic aeolian Tumlin Sandstone, central Poland. Palaeogeography, Palaeoclimatology, Palaeoecology 108(1-2): 121-138.

Hoff, K.V., N. Huq, V.A. King, and R.J. Wassersug. 1989. The kinematics of larval salamander swimming (Ambystomatidae: Caudata). Canadian Journal of Zoology 67(11): 2756-2761.

Ijspeert, A.J., A. Crespi, and J.M. Cabelguen. 2005. Simulation and robotics studies of salamander locomotion. Neuroinformatics 3(3): 171-195.

Jordan, P.A., R.O. Peterson, and K.A. LeDoux. 2010. Swimming wolves, Canis lupus, attack a swimming Moose, Alces alces. The Canadian Field-Naturalist 124(1): 54-56.

King, M.J., W.A.S. Sarjeant, D.B. Thompson, and G. Tresise. 2005 A revised systematic ichnotaxonomy and review of the vertebrate footprint ichnofamily Chirotheriidae from the British Triassic. Ichnos 12(4): 241-299.

Kuleta, M., and J. Nawrocki. 2000. Litostratygrafia i magnetostratygrafia pstrego piaskowca w pótnocnym obrzezeniu Gór Świętokrzyskich. Kielce-Warszawa: CAG Państwowy Instytut Geologiczny.

Kuleta, M., G. Niedźwiedzki, and T. Ptaszyński. 2005. Nowe stanowisko z tropami kręgowców z górnego pstrego piaskowca Gór Świętokrzyskich. Przeglad Geologiczny 53(2): 2-6.

Leonardi, G., and F.H. de Oliveira. 1990. A revision of the Triassic and Jurassic tetrapod footprints of Argentina and a new approach on the age meaning of the Botucatu Formation footprints (Brasil). Revista Brasileira de Geociencias 2(4): 216-229.

Lockley, M.G. 1991. Tracking dinosaurs: A new look at an ancient world. Cambridge: Cambridge University Press.

Lockley, M.G., and J.R. Foster. 2006. Dinosaur and turtle tracks from the Morrison Formation (Upper Jurassic) of Colorado National Monument, with observations on the taxonomy of vertebrate swim traces. In Paleontology and Geology of the Upper Jurassic Morrison Formation, eds. J.R. Foster and S.G. Lucas. New Mexico Museum of Natural History and Science, Bulletin 36: 193-198.

Maglischo, E.W. 2003. Swimming fastest. Champaign: Human Kinetics.

Matsuuchi, K., T. Miwa, T. Nomura, J. Sakakibara, H. Shintani, and B.E. Ungerechts. 2009. Unsteady flow field around a human hand and propulsive force in swimming. Journal of Biomechanics 42(1): 42-47.

McAllister, J. 1989. Subaqueous vertebrate footmarks from the upper Dakota Formation (Cretaceous) of Kansas, USA. Kansas: 
Museum of Natural History Occasional Papers, University of Kansas.

McAllister, J., and J. Kirby. 1998. An occurrence of reptile subaqueous traces in the Moenkopi Formation (Triassic) of Capitol Reef National Park, south central Utah, USA National Park Service, Technical Report NPS/NRGRD/GRDTR-98/1 98, 45-49.

McCrea, R.T., S.G. Pemberton, and P.J. Currie. 2004. New ichnotaxa of mammal and reptile tracks from the Upper Paleocene of Alberta. Ichnos 11(3-4): 323-339.

McDowall, R.M. 2003. Variation in vertebral number in galaxiid fishes, how fishes swim and a possible reason for pleomerism. Reviews in Fish Biology and Fisheries 13(3): 247-263.

Minetti, A.E., G. Machtsiras, and J.C. Masters. 2009. The optimum finger spacing in human swimming. Journal of Biomechanics 42(13): 2188-2190.

Minter, N.J., and S.J. Braddy. 2006. The fish and amphibian swimming traces Undichna and Lunichnium, with examples from the Lower Permian of New Mexico, USA. Palaeontology 49(5): 1123-1142.

Nelson, M.E., and L.D. Mech. 1984. Observation of a swimming wolf killing a swimming deer. Journal of Mammalogy 65(1): 143-144.

Nicosia, U., and M. Loi. 2003. Triassic footprints from Lerici (La Spezia, Northern Italy). Ichnos 10(2-4): 127-140.

Niedźwiedzki, G., and T. Ptaszyński. 2007. Large Chirotheriidae tracks in the Early Triassic of Wióry, Holy Cross Mountains, Poland. Acta Geologica Polonica 57(3): 325-342.

Peabody, F.E. 1947. Current crescents in the Triassic Moenkopi Formation (Arizona). Journal of Sedimentary Research 17(2): 73-76.

Pollard, J.E. 1985. Isopodichnus, related arthropod trace fossils and notostracans from Triassic fluvial sediments. Transactions of the Royal Society of Edinburgh, Earth Sciences 76: 272-285.

Provini, P., P. Goupil, V. Hugel, and A. Abouraqchid. 2012. Walking, Paddling, Waddling: 3D Kinematics Anatidae Locomotion (Callonetta leucophrys). Journal of Experimental Zoology Part A: Ecological Genetics and Physiology 317(5): 275-282.

Ptaszyński, T. 2000. Lower Triassic vertebrate footprints from Wióry, Holy Cross Mountains, Poland. Acta Palaeontologica Polonica 45(2): 151-194.

Sarjeant, W.A.S. 1975. Fossil tracks and impressions of vertebrates. In The study of trace fossils: A synthesis of principles, problems, and procedures in ichnology, ed. R. Frey, 283-324. Berlin: Springer.

Seebacher, F., P.G. Elsworth, and C.E. Franklin. 2003. Ontogenetic changes of swimming kinematics in a semi-aquatic reptile (Crocodylus porosus). Australian Journal of Zoology 51(1): 15-24.

Shukla, U., G. Bachmann, G. Beutler, J. Barnasch, and M. Franz. 2006. Extremely distal fluvial sandstone within the playa system of Arnstadt Formation (Norian, Late Triassic), central Germany. Facies 52(4): 541-554.

Sidelnik, N.O., and B.W. Young. 2006. Optimizing the freestyle swimming stroke: the effect of finger spread. Sports Engineering 9(3): 129-135.

Simon, T., H. Hagdorn, M.K. Hagdorn, and A. Seilacher. 2003. Swimming trace of a coelacanth fish from the Lower Keuper of SouthWest Germany. Palaeontology 46(5): 911-926.
Somers, M.J., and M.G. Purves. 1996. Trophic overlap between three syntopic semiaquatic carnivores: cape clawless otter, spottednecked otter and water mongoose. African Journal of Ecology 34(2): 158-166.

Sweeney, J.R., R.L. Marchinton, and J.M. Sweeney. 1971. Responses of radio monitored white-tailed deer chased by hunting dogs. The Journal of Wildlife Management 35(4): 707-716.

Thomson, T.J., and M.L. Droser. 2015. Swimming reptiles make their mark in the Early Triassic: Delayed ecologic recovery increased the preservation potential of vertebrate swim tracks. Geology 43(3): 215-218.

Thomson, T.J., and D.M. Lovelace. 2014. Swim track morphotypes and new track localities from the Moenkopi and Red Peak formations (Lower-Middle Triassic) with preliminary interpretations of aquatic behaviors. New Mexico Museum of Natural History and Science Bulletin 62: 103-128.

Thulborn, R.A., and M. Wade. 1989. A footprint as a history of movement. In Dinosaur tracks and traces, eds. D.G. Gillette and M.L. Lockley, 51-56. Cambridge: Cambridge University Press.

Vallon, L.H., A.K. Rindsberg, and R.G. Bromley. 2016. An updated classification of animal behaviour preserved in substrates. Geodinamica Acta 28(1-2): 5-20.

Vila, B., D. Castanera, J. Marmi, J.I. Canudo, and A. Galobart. 2014. Crocodile swim tracks from the latest Cretaceous of Europe. Lethaia 48(2): 256-266.

Walker, R.G., and J.C. Douglas. 1984. Sandy fluvial systems. In Facies models, 2nd ed, ed. R.G. Walker, 71-89. Toronto: Geoscience Canada.

Webb, P. 1988. Simple physical principles and vertebrate aquatic locomotion. Integrative and Comparative Biology 28(2): 709-725.

Whyte, M.A., and M. Romano. 2001. A dinosaur ichnocoenosis from the Middle Jurassic of Yorkshire, UK. Ichnos 8(3-4): 223-234.

Williams, T.M. 1983. Locomotion in the North American mink, a semi-aquatic mammal. I. Swimming energetics and body drag. Journal of Experimental Biology 103(1): 155-168.

Willson, J.D., C.T. Winne, M.E. Dorcas, and J.W. Gibbons. 2006. Post-drought responses of semi-aquatic snakes inhabiting an isolated wetland: insights on different strategies for persistence in a dynamic habitat. Wetlands 26(4): 1071-1078.

Wisshak, M., E. Volohonsky, and D. Blomeier. 2004. Acanthodian fish trace fossils from the Early Devonian of Spitsbergen. Acta Palaeontologica Polonica 49(4): 629-634.

Xing, L., M. Avanzini, M.G. Lockley, T. Miyashita, H. Klein, J. Zhang, Q. He, L. Qi, J.D. Divay, and C. Jia. 2014. Early Cretaceous turtle tracks and skeletons from the Junggar basin, Xinjiang, China. Palaios 29(4): 137-144.

Yeager, C.P. 1991. Possible antipredator behavior associated with river crossings by proboscis monkeys (Nasalis larvatus). American Journal of Primatology 24(1): 61-66. 